\title{
Returns, setbacks, and future prospects of bio-energy promotion in northern Ethiopia: the case of family-sized biogas energy
}

\author{
Haftu Etsay Kelebe
}

\begin{abstract}
Background: Solid biomass-based energy is expected to retain its position as a sole fuel source for households in the rural part of Ethiopia unless alternative energy sources are introduced. Synthesizing small-scale renewable alternative energy sources, such as biogas energy, into the energy mix has become an important strategy to overcome the energy hunger of its rural residents. As part of the government policy, small-scale biogas digesters have been installed in selected districts and regions of the country since 2007. There is, however, limited evidence on whether or not the intended objectives of the domestic biogas initiative have been actualized by the participants of the project. This paper, therefore, intends to investigate the economic benefits of domestic biogas plants along with the challenges facing it and future prospects of the biogas initiative in selected districts of northern Ethiopia.

Methods: Qualitative data were gathered using focus group discussion and key informant interviews. A survey of 400 households was also administered to capture cross sectional data using structured questionnaires. The qualitative data were analyzed using content analysis. A propensity score matching model was employed to evaluate the effects of domestic biogas technology on energy expenditure, crop yield, and the substitution of chemical fertilizers.

Results: The study finds that biogas adopters have reduced their monthly energy expenditure on average by 20-36\%. Moreover, the existence of a positive crop yield premium of 1.5 quintal/year/household was observed as a result of using bio-slurry as a fertilizer. The key factors that limit the extension of biogas technology to potential biogas adopters are the presence of failed digesters, an inadequate plot of land for the digester construction and a water availability problem. In light of such barriers, however, the study finds that more favorable environments for the widespread use of the technology exist.
\end{abstract}

Conclusions: Biogas user households have significantly reduced their energy expenditure compared to non-biogas adopters. Nevertheless, despite the modest increase in crop yield, the overall effect of bio-slurry application on crop productivity and substituting chemical fertilizers was not significant because of an improper bio-slurry utilization and management.

Keywords: Biogas energy, Bio-slurry, Energy expenditure, Future prospects, Tigrai 


\section{Background}

In developing countries, around 2.5 billion people rely on solid biomass such as fuel wood, charcoal, agricultural waste, and animal dung to meet their energy needs, primarily for cooking and lighting [1]. In many countries, particularly in rural areas, these resources account for over $90 \%$ of household energy consumption [2]. Such a high biomass energy consumption habit in developing countries has resulted in various environmental problems like deforestation, soil erosion, and poverty [3, 4]. A report by the FAO [5], for instance, shows that $5 \%$ of global deforestation is due to fuel wood consumption, and $55 \%$ of the wood extracted from forests is used for fuel purposes.

Sub-Saharan Africa (SSA) in particular is the highest sub-region in terms of biomass energy utilization, which accounts for about $85-95 \%$ of total energy, whereas $60-90 \%$ is used for the developing world as a whole $[6,7]$. In this sub-region where traditional energy sources entirely satisfy the majority of the energy needs of rural households, biogas technology can be viewed as one of the renewable and sustainable technologies to reduce its energy hunger and environmental problems [8]. The author further asserts that African countries have a tremendous biogas potential as it is produced from agricultural residues, is relatively simple and can operate on a small and a large scale in both urban and rural locations. Moreover, the majority of people in SSA also exceedingly depend on combustibles for domestic cooking and heating purposes. Combustible renewable energy resources, in particular charcoal, wood fuel, dried crop, and animal residues, have environmental and health effects due to its incomplete combustion [9]. There have been global and continental initiatives towards the development and promotion of alternative energy sources in the past three decades to address the adverse impacts of solid biomass energy consumption [10]. The important continental initiative in Africa is the "Africa Biogas Partnership Programme," which was launched in 2007 to disseminate small-scale biogas plants in selected countries of the continent. The Africa Biogas Partnership Programme is a partnership between two Dutch non-profit organizations, Humanist Institute for Development Cooperation (Hivos) and the Netherlands Development Organization (SNV), which supports domestic biogas programs in ten SSA countries, of which Ethiopia is one among the beneficiaries of the program [11].

Ethiopia's energy challenges have been described as acute despite the availability of a large energy reserve in the country. This energy scarcity problem is manifested mainly in the form of a very low per-capita electricity consumption and the dominance of the use of traditional biomass fuels. There are reports which show that the per-capita energy supply and consumption of
Ethiopia is lower than even that of most of the sub-Saharan African countries. A report by the International Energy Organization [12], for example, shows that the per-capita total primary energy supply in Ethiopia was merely 0.4 ton of the oil equivalent while the average for Africa amounted to 0.67 in 2011. The same source also indicates that the annual per-capita electricity consumption in Ethiopia was only $55 \mathrm{kWh}$ while it was $592 \mathrm{kWh}$ for the whole of Africa. Moreover, the percentage of population who relied on the traditional use of biomass fuel for cooking was 93\% in Ethiopia in 2009, while it was $65 \%$ in Africa, $77 \%$ in sub-Saharan Africa, and $39 \%$ in the world as a whole [13]. This overdependence on traditional fuel sources in Ethiopia has significantly contributed to severe environmental degradations such as deforestation, soil degradation, and loss of bio-diversity [14]. It is anticipated that traditional biomass fuels will continue to be the primary cooking fuels in most rural communities of the country at least in the near future. Hence, reducing energy-poverty in such context depends on the scale of utilizing technologies that minimize the harmful effects of traditional biomass fuels. Among others, the use of biogas energy has been indicated to be vital to increase cooking efficiency, reduce smoke, reduce solid fuel wood consumption, and improve the overall safety of rural households [14].

Biogas energy is generated through anaerobic digestion. It contains mainly methane (50-70\%) while the rest is mostly carbon dioxide and a small amount of other gases [15]. Anaerobic digestion converts human excreta, animal dung and other agricultural residues into a clean and environmentally friendly energy commodity. Biogas has also been recognized as a technology with the potential for vast environmental, economic, and health benefits [16]. Regarding the environmental benefits, anaerobic digestion can significantly lower greenhouse gas emissions from manure and direct combustion of solid fuel wood. In addition to this, by substituting the solid fuels commonly used for cooking in developing countries, such as wood and charcoal, alleviates pressure on the forests [17]. Furthermore, using biogas energy as a substitute for fossil fuels can significantly reduce the amount of greenhouse gas emissions. It also saves substantial time by reducing fuel wood collection and cooking times [18]. The technology can also offer substantial economic benefits especially to women, who are the prime victims of dirty fuel use [19]. Apart from the production of biogas (methane), anaerobic digestion transforms the added feedstock into a bio-slurry that can be used as an organic fertilizer and substitute chemical fertilizer for crop production. It is, therefore, apparent that biogas technology essentially meets most of the key requirements for addressing the energy access and environmental problems. It also provides some economic 
gains. Biogas technology can also be applied wherever there are sufficient organic and locally available materials. However, the concern of many stakeholders of the biogas program cannot be neglected, who ask why the diffusion of the technology remains low and abandoned in many parts of Ethiopia despite the international and national efforts to promote the technology in that place.

Many studies have been conducted dealing with the benefits and barriers of biogas technology in some regions of Ethiopia. Regarding its potential, for instance, Kamp and Forn [20] stated that the physical geography of many parts of Ethiopia complies with the technical criteria of the operation of biogas plants in terms of temperature and availability of waste organic matter. Similarly, the availability of cheap feedstocks from livestock and agricultural residues are reported to be the country's future potential for installing small-scale biogas technology [21]. On the contrary, some other literature data show that socio-economic attributes, demography, technical challenges, and institutional barriers are the major challenges facing biogas technology in Ethiopia $[20,22,23]$. Besides, lack of properly educated personnel, inadequate access to biogas appliances and accessories, poor private sector participation, inadequate maintenance and repair services, and poor quality of digesters are also found to be serious bottlenecks that inhibit the diffusion of the technology in east Africa and particularly in Ethiopia, Rwanda, and Uganda [24-28]. On the other side, there are also studies conducted in terms of the incentives towards the promotion of biogas technology in sub-Saharan Africa and in Ethiopia in particular. According to Amigun et al. [29], biogas adopters in Ethiopia have already started experiencing the benefits of the project; such as the use of clean cooking fuel and income savings made in terms of time and money to search for fuel and to purchase other traditional fuels (fire wood, charcoal, and kerosene), thereby motivating other potential biogas users to adopt.

In light of such benefits, this paper asks the critical question of why the widespread dissemination of this technology has been prevented, as the previous studies in the Tigrai region did not fully address whether or not the intended objectives of the domestic biogas program of Ethiopia have been actualized by the participants. The aim of this paper, which focuses on smallholder farmers in Northern Ethiopia, is therefore to examine the impact of the domestic biogas program on the three main outcomes: whether the access to a domestic biogas plant leads to reductions in energy-related expenditure, whether it affected the crop yield and substitution of chemical fertilizer, and what are the challenges facing the already installed biogas plants and the future potential for the extension of the domestic biogas technology in the Tigrai region.

\section{Theoretical framework}

The basic theoretical framework underlying this study evolves from the theory of energy stacking, particularly transition and multiple uses of energy sources. According to the existing literature, there are two well-established and of course contradicting views to be found in energy transition models on how households move towards the use of modern fuels. These include energy ladder and energy stacking hypotheses [30,31]. The former one is built on the idea that modern fuels are considered to have more advantages than the traditional fuels in many standards, and are thus considered to be higher rungs on the ladder. The main argument of this theory is that households switch from traditional fuels to transition fuels (such as charcoal, kerosene, and bio-fuels), and later on to modern fuels (such as liquefied petroleum gas (LPG) and electricity) as a result of a rise in income. In short, the model hypothesizes that households move along the energy ladder as their income increases. More recently, however, various studies have reported a number of pitfalls especially in the applicability of the theory of the energy ladder in developing countries and in particular in a rural setting. Odihi [32], for instance, has discussed the challenges with regard to the practicability of this model in developing countries for the obvious reasons that the presence of both inadequate fuel distribution and energy facilities are beyond the reach of many households regardless of their level of income.

In reality, in developing countries particularly in rural areas, households do not linearly switch to modern fuels with a rise in income since the choice of fuels is not determined solely by disposable income [33, 34]. According to the energy stacking model, households may develop a stacking behavior so that they can use more than one fuel type simultaneously instead of simply substituting the earlier ones. Besides, the energy ladder theory has been contested in various literatures mainly for the following reasons. The first reason, as the multiple fuel use behavior of households is not considered in the energy ladder model. In developing countries, because of an unreliable supply of modern energy, households prefer to use a mix of energy to be on the safe side during the times when primary energy sources are not easily available. Secondly, the multi-purpose nature of various energy sources is also an important concept that determines the decision of households towards fuel preference. This factor has also been overlooked by the existing energy transition concepts. Nevertheless, the energy stacking model has been reported to be a more acceptable theoretical framework to explain the adoption behavior of households in developing countries [34-37]. There are some energy sources which may have important contributions not only in solving the energy problem but also in playing a pivotal role in other sectors. For 
instance, the by-products of some of the biofuels are useful for agriculture (soil fertility enhancement and forage for livestock). The existing energy transition models do not take into consideration such multiple services of a given energy source when explaining the behavior of households towards the preferences of fuels.

In this paper, the research focus is on the concept of energy transition constraints and multiple uses of energy sources, which are considered to be important variables that explain the household behavior towards the use of fuels among a set of energy options. The study addresses the key constraints and prospects of transition towards biofuels and how the multi-purpose nature of biofuels determines the preference of households towards various energy options by taking family-sized biogas digesters as a case study, as its energy technology produces biogas energy (methane) and organic fertilizer (bio-slurry) which is useful for enhancing crop production by substituting chemical fertilizer.

\section{Methods}

\section{Study sites}

The study was conducted in three randomly selected districts of the Tigrai region. These are Ofla, Hintalo-Wajerat, and Enderta, where domestic biogas technology has recently been introduced by the National Domestic Biogas Programme of Ethiopia. The study areas are spatially distributed across three districts to capture heterogeneous data on socio-economic attributes, energy consumption patterns and biomass energy potentials. The study sites are also characterized by various climatic and topographical domains ranging from altitude differences to temperature and rainfall variations as well as endowment of biomass energy sources. The farming system, which was observed to be a mix of livestock and crop production in all study sites, is also among the sources of traditional energy. The energy consumption pattern across the three study sites is observed to be fairly similar which is in fact dominated by biomass energy.

\section{Sample design, procedures, and data collection}

The study areas were selected using multi-stage sampling techniques. In the first stage of the sampling procedure, the three districts were randomly selected. Then after, based on the number of domestic biogas plants installed, two high-achieving "tabias" from each district were purposively chosen with a support of experts from the office of mining and energy of the study districts. The sampling frame for this study was households who use the end products of domestic biogas technology (methane and bio-slurry) for fuel and fertilizer purposes. A simple random sampling technique was then applied to select the respondents from the list of biogas user households (hereafter referred as treated observations) and non-biogas user households (hereafter referred to as control observations) of each selected "tabia."

This study used a cross-sectional survey of 400 randomly drawn households, both treated and control observations comprised of 200 each, from 3 districts and 6 tabias carried out between February and April, 2016. The sample for the treated observations was drawn from a set of 1887 households, which introduced a family-sized biogas plant in the three districts as of December, 2015. An attempt was made to include digesters whose construction had been completed at least 6 months prior to the survey with an intention that this time lag provided adequate time for households to develop the experience needed to operate a digester and at the same time experience the benefits of owning a small-sized biogas plant. The majority of the biogas users (1061) were from the Hintalo-Wajerat district. The Ofla and Enderta districts also had 516 and 310 biogas users, respectively, during the survey. Following Watson [38], this study adopts Eq. 1 to calculate the representative sample size from the target population. The distribution of the sample size across the districts was based on their relative share of the biogas users to the total sampling frame (target population) as shown in Table 1.

$$
n=\frac{p(1-p)}{\frac{e^{2}}{Z^{2}}+\frac{p(1-p)}{N}}
$$

where $n=$ sample size.

$N=$ target population (1887).

$e=$ precision level (0.065).

$\mathrm{Z}=1.96$, confidence level at $95 \%$.

$P=0.5$, estimated population proportion

$$
n=\frac{0.5(1-0.5)}{\frac{0.065^{2}}{1.96^{2}}+\frac{0.5(1-0.5)}{1887}} \quad n=200
$$

The required data were collected from the selected heads of households using structured questionnaires. Focus group discussions, key informant interviews, and field observations were also used to validate the household survey and to acquire in-depth qualitative data. A

\begin{tabular}{|c|c|c|c|c|}
\hline \multirow[t]{2}{*}{ Study site } & \multirow{2}{*}{$\begin{array}{l}\text { Target } \\
\text { population }\end{array}$} & \multicolumn{3}{|l|}{ Sample size } \\
\hline & & $\begin{array}{l}\text { Biogas users } \\
\text { (treatment) }\end{array}$ & $\begin{array}{l}\text { Non-biogas users } \\
\text { (control) }\end{array}$ & Total \\
\hline Ofla & 516 & 55 & 55 & 110 \\
\hline Hintalo-Wajerat & 1061 & 112 & 112 & 224 \\
\hline Enderta & 310 & 33 & 33 & 66 \\
\hline Total & 1887 & 200 & 200 & 400 \\
\hline
\end{tabular}

Table 1 Sample size from each study site 
pre-tested questionnaire was deployed to gather the data with regard to a wide range of socio-economic aspects and household demographics, occupation, education, cooking behavior, energy-related expenses, and fuel use. In addition, the questionnaire contained a section about the reasons for (not) adopting biogas, the source of funds for the digester and follow up and technical supports by the National Biogas Programme of Ethiopia. Furthermore, qualitative data on challenges and opportunities of the biogas sector were acquired using focus group discussions and key informant interviews. The secondary data were collected from published articles and unpublished governmental reports; in particular, reports of the National Biogas Programme of Ethiopia, the Tigrai Regional Biogas Programme Coordination Office and the Central Statistical Agency of Ethiopia.

\section{Data analysis}

To analyze the trends, impediments and prospects of the biogas sector, a content analysis was used. Descriptive statistics such as measures of central tendency and dispersions were employed. Statistical tests (mainly $t$ tests) were also deployed to determine the differences between treated and control observations in regard to various socio-economic attributes. In order to analyze the impact of the biogas technology intervention on energy expenditure, crop yield and uptake of chemical fertilizer, propensity score matching was deployed to reduce the possible sampling bias as the participation in the domestic biogas program is not random.

\section{Propensity score matching model (PSM)}

There are two main concerns with regard to the participation in a biogas program in relation to employing PSM for the analysis in this study. First, the biogas initiative is voluntary and households need to apply for a biogas plant. Second, conditional on application, program beneficiaries are not selected at random but need to fulfill the eligibility conditions such as ownership of at least four cattle (local bread) to ensure adequate cattle dung for anaerobic digestion and an adequate space for the biogas digester tank to be built. Due to these two reasons, self-selection to participate in the program and the imposition of eligibility conditions, it is more likely that those who apply and obtain a biogas plant are systematically different from those who do not. Hence, comparison between households who have a biogas plant and those who do not, without accounting for potential differences in factors that determine selection into the program are more likely to yield incredible estimates.

To capture such a problem of biasedness, households that have participated in the national domestic biogas program of Ethiopia were basically compared to those that have not yet participated in employing the propensity score matching model. The treatment in this case is participating in the domestic biogas program where the outcomes were change in energy expenditure, uptake of chemical fertilizer and crop yield. The study passed through two steps to analyze the impact of the domestic biogas initiative on the outcome variables. Initially, following Becher and Ichino [39], the probability of installing a domestic biogas plant, also known as the propensity score, for the treated and control observations was estimated by means of selection Eq. 2 that uses a binary logit model (Table 5). The full lists of explanatory variables included in this study are presented in Table 2 . The second step was computing the average treatment effect on treated (ATT) over the outcome of Eq. 5; (where the ATT is the average effect of the treatment for cases that are treated and must average over the outcomes of treatment for the treated observations $(\mathrm{Y} 1 \mid T=1)$ presented in Eq. 5. This means that ATT is the average difference in energy expenditure, crop yield, and uptake of chemical fertilizer between households with and without biogas energy after matching (Tables 6 and 7). This was achieved by matching biogas user and non-user households according to their propensity score using the nearest neighbor, radius, kernel, and stratification matching methods as suggested by Becker and Ichino [39].

Treatment $\mathrm{D}$ is a binary variable that determines if the household uses biogas technology or not, $D=1$ for the users and $D=0$ otherwise.

$X_{i}$ denotes the pre-treatment characteristics (characteristics of households that might affect the adoption decision of biogas technology).

$$
P\left(X_{i}\right)=\operatorname{prob}\left(D=1 / X_{i}\right)=E\left(D / X_{i}\right)
$$

Eq. 2 indicates that the probability of adoption decision of households towards biogas technology is conditional to the pre-treatment characteristics of households.

$$
y=\left\{\begin{array}{l}
y_{1} \text { if } D=1 \\
y_{0} \text { if } D=0
\end{array}\right.
$$

In Eq. 3, $Y$ denotes the treatment effects (impact of adopting biogas technology on energy expenditure, crop yield, and utilization of chemical fertilizer). In order to know what would have happened to the outcome variables (energy expenditure, crop yield, and uptake of chemical fertilizer) had the households not used biogas energy and bio-slurry, the outcome $Y$ among the participants $\left(Y_{1}\right)$ and non-participants $\left(Y_{0}\right)$ after matching ought to be compared.

Average treatment effect (ATE): The ATE shows the difference between the average energy consumption, crop 
Table 2 Description of the independent variables used to explain the probability of adopting biogas technology

\begin{tabular}{|c|c|c|c|}
\hline $\begin{array}{l}\text { Name of } \\
\text { the variable }\end{array}$ & $\begin{array}{l}\text { Nature of } \\
\text { the variable }\end{array}$ & $\begin{array}{l}\text { Hypothesized relationship with } \\
\text { the dependent variable (biogas adoption) }\end{array}$ & Description of the variable \\
\hline Age & Continuous & Positive/negative & Age of the household head in years \\
\hline Sex & Dummy & Positive/negative & $\begin{array}{l}\text { Sex of the household head; a dummy variable for } \\
\text { gender relationships (male }=1 \text {, female }=0 \text { ) }\end{array}$ \\
\hline Family size & Continuous & Positive/negative & Family size of the household \\
\hline Education & Continuous & Positive & Education level of the household head in years \\
\hline Cattle holding & Continuous & Positive & Number of cattle owned by the household (heads/hh) \\
\hline Annual income & Continuous & Positive & Annual income of the household in ETB \\
\hline DistFire & Continuous & Positive & Distance to nearest firewood collection site in kilometer \\
\hline DistWater & Continuous & Negative & Distance to nearest permanent water point in kilometer \\
\hline DistMarket & Continuous & Positive/negative & Distance to nearest market in kilometer \\
\hline $\begin{array}{l}\text { Availability of } \\
\text { electricity }\end{array}$ & Dummy & Negative & Availability of modern fuels mainly electricity (yes $=1$, otherwise $=0$ ) \\
\hline Farm size & Continuous & Positive & Total size of farm plots owned and operated by the household in Tsimad \\
\hline Fertility status & Categorical & Positive/negative & Fertility status of farm plot $(1=$ poor, 2 = medium, $3=$ good $)$ \\
\hline Farm location & Continuous & Negative & Distance between house and farm of the household in kilometer \\
\hline Extension service & Continuous & Positive & $\begin{array}{l}\text { Frequency of contacts between agricultural extension worker and } \\
\text { the household (frequency in a year) }\end{array}$ \\
\hline
\end{tabular}

yield, and chemical fertilizer among the biogas user and non-user households without matching as shown in Eq. 4.

$$
\begin{aligned}
& \Delta=y_{1}-y_{0} \\
& A T E=E(\Delta)=E\left(y_{1} \mid x, D=1\right)-E\left(y_{0} \mid x, D=0\right)
\end{aligned}
$$

Equation 4 may be biased in case the treated and control variables are not similar, which is obvious in observational studies in contrast to experimental studies. To overcome this problem, it is recommended to use the average treatment effect on the treated cases (Eq. 5).

Average treatment effect on the treated (ATT): Eq. 5 is a counterfactual situation which compares the average energy expenditure, crop yield, and uptake of chemical fertilizer of the biogas adopter and non-adopter households after matching based on their propensity scores to adopt biogas energy technology.

$$
\begin{aligned}
\mathrm{ATT} & =(E(\Delta) \mid p(x), D=1) \\
& =E\left(y_{1} \mid p(x), D=1\right)-E\left(y_{0} \mid p(x), D=0\right)
\end{aligned}
$$

\section{Results and discussion}

\section{Description of the sampled households}

Table 3 summarizes the socio-economic and demographic attributes of sampled households. There is a significant difference between the biogas user and non-user households in many of the socio-economical and demographical variables that are included in this study. For instance, the average age, level of education, family size, farm size, and annual income of the treated cases (biogas users) were found to be significantly higher compared to that of the comparison observations as shown in Table 3. More specifically, households who adopted biogas technology are found to be older than their non-adopter counterparts. This gives the impression that older households tend more to use better energy sources such as biogas energy due to the possibility of a better wealth accumulation compared to the youngsters. The profile of the households also indicates that the biogas user households were found to have higher educational attainments than that of non-users, which implies education is a key element for modern technology adoption and use. Besides, the average farm size of biogas users and non-users was 2.5 and $2 t_{\text {simad }}^{2}$ respectively with a significant difference between the two groups. Similarly, biogas users were found to have higher annual income and family size than that of non-user households which highlights that higher income may be associated with the utilization of better energy facilities. The descriptive statistics of this study confirms that households that have already adopted biogas technology have higher incomes than that of non-adopters (Table 3). The coefficient of binary logit regression (Table 5) also confirms a positive and significant relationship between the two variables. This implies that a rise in income of households may cause a partial shift to relatively better energy sources such as biogas technology. On the other hand, a households' income rises as a result of reduction in energy expenditure. Therefore, a bi-directional relationship between income and biogas adoption is evident. 
Table 3 Mean value of basic socio-economic and demographic variables of respondents (standard deviation in parentheses)

\begin{tabular}{|c|c|c|c|c|}
\hline Variables & Treated observations $(n=200)$ & Control observations $(n=200)$ & Total sample $(n=400)$ & $P$ value \\
\hline Sex of the household head (female $=0$, male $=1$ ) & $0.86(0.34)$ & $0.89(0.31)$ & $0.87(0.33)$ & - \\
\hline Age of the household head in years & $47(9.18)$ & $45(10.3)$ & $46(9.8)$ & 0.03 \\
\hline $\begin{array}{l}\text { Education level of the household head (years of } \\
\text { schooling) }\end{array}$ & $2.5(2.7)$ & $1.5(2.4)$ & $2(2.64)$ & 0.000 \\
\hline Household size & $6.3(1.68)$ & $5.7(1.77)$ & $6(1.75)$ & 0.001 \\
\hline Farm size in tsimad & $2.5(1.32)$ & $2.07(1.57)$ & $2.3(1.47)$ & 0.000 \\
\hline Cattle holding in heads & $5(2.73)$ & $5(3.24)$ & $5(2.99)$ & 0.32 \\
\hline Annual income in ETB & $18,949.78(12910)$ & $14,175.5(8287.5)$ & $16,562.6(11095)$ & 0.000 \\
\hline
\end{tabular}

The study shows that there were no statistically significant differences observed in the cattle holding between the two observations signaling that availability of feedstock is no longer a challenge for a biogas adoption decision at the study sites since the average cattle holding for both observed cases was 5 heads which is quite higher than the minimum heads of cattle required to operate a $6 \mathrm{~m}^{3}$ biogas digester (according to National Biogas Programme of Ethiopia, a minimum of 4 heads of cattle is required in the context of the rural part of the country.

\section{Challenges facing the biogas technology and future prospects}

The household survey shows that inadequate energy (methane) production, frequent damage of installed digesters and inadequate institutional support are the major challenges hampering the smooth operation of biogas plants which account for $32 \%, 31 \%$, and $22 \%$ of the total biogas user respondents, respectively (Table 4). These figures imply that a considerable number of biogas digester owners face technical-related challenges, as a low level of energy production and damage of the biogas system usually induced by technical related faults. The report of the National Biogas Programme of Ethiopia [40] also shows that the uptake of biogas technology is lagging behind the target which strengthens the findings of the household survey (Fig. 1). Despite the plan to install 15,100 domestic digesters in four regional states of Ethiopia from 2008 to 2014, only 63\% of the plan was achieved. Similarly, in the Tigrai region alone, where this study was conducted, 3873 domestic biogas digesters have been built compared to the planned 5288 digesters, which is $73 \%$ of that which was targeted to be installed. Therefore, the uptake of biogas diffusion over the past years seems to have experienced irregularities at the regional (Tigrai) and district levels. This report may also be considered as an indicator that the technology has been hurdled by the above stated barriers. Figure 1 shows that during the early periods of the biogas initiative, the uptake increased and reached its peak in 2013. Since then, however, it faces stagnation and in fact slowed down in some of the study sites. This could also be considered as an indicator of the technical challenges that faces the installed digesters. Besides, key informants frequently reported that bad habits such as irregular or insufficient feeding of the bio-digester significantly hinder biogas production and eventually stop working. The presence of such non-operating digesters in neighborhoods definitely influenced the promotion of the technology due to spillover effects as many people are more curious about bad stories than success stories of a new technology. A study by Parawira [8] supports the findings of the current study by disclosing that low performance and poor quality of installed plants contributed to the dis-adoption of biogas digesters in sub-Saharan Africa. Moreover, the current findings comply with Eshetie et al. [21] who reported that the major

Table 4 Major challenges and future prospects towards the transition of domestic biogas energy

\begin{tabular}{ll}
\hline Variables & Percent ${ }^{*}$ \\
\hline Challenges facing installed digesters $(n=200)$ & \\
Low energy production & $32 \%$ \\
Damage of installed digesters & $31 \%$ \\
Inadequate institutional support & $22 \%$ \\
Shortage of manure & $15 \%$ \\
Reasons for not adopting biogas technology $(n=200)$ & \\
Lack of feedstock & $13 \%$ \\
High cost of construction & $24 \%$ \\
No credit access & $13.8 \%$ \\
Spillover effect of failed digesters & $52.3 \%$ \\
No space for digester pit preparation & $48.5 \%$ \\
Water problem & $37.6 \%$ \\
Limited knowhow & $14.2 \%$ \\
Favorable conditions for wider promotion of biogas technology $(n=400)$ \\
Availability of cheap feedstocks & $39 \%$ \\
Existence of subsidy for the technology & $25.5 \%$ \\
Multifaceted benefits of the technology & $39.9 \%$ \\
Scarcity of solid fuels & $44.5 \%$ \\
Increase the price of solid and fossil fuels & $36.2 \%$ \\
\hline
\end{tabular}

*Multiple responses is possible, $n$ stands for number of respondents 


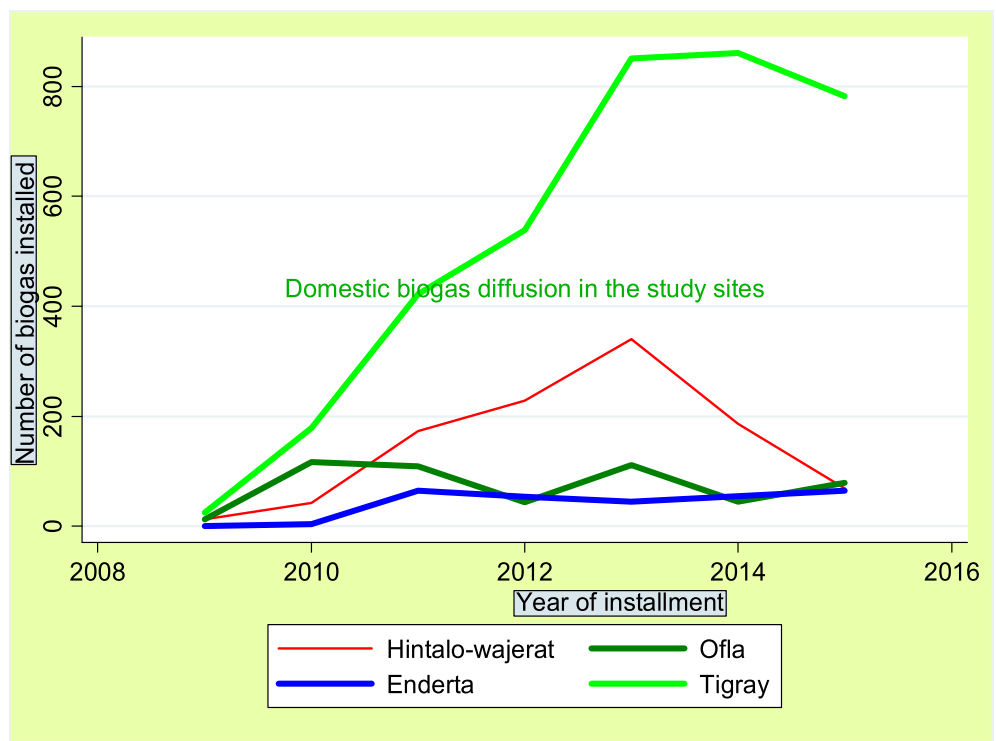

Fig. 1 Uptake of biogas technology in Tigrai region and study districts

bottlenecks facing the extension of the biogas technology include technical problems, abandonment, and loss of interest.

Regarding the reasons for not adopting biogas technology, the surveyed non-biogas adopters responded that the spillover effect of failed digesters (52.3\%), inadequate space for pit preparation (48.5\%), and water problems $(37.6 \%)$ constituted the core issues (Table 4). It was also observed during the field survey that a substantial number of digesters were not operating at all study sites. This might have contributed to the sluggish behavior of many eligible households for not participating in the domestic biogas program. Lack of a permanent water supply in the nearby area was also reported to be a challenge for potential adopters. Anaerobic digestion normally consumes a considerable amount of water, which is a proportion equal to the amount of manure to be loaded into the digester. It is, therefore, unlikely for households to adopt biogas energy without ensuring a permanent water supply within a reasonable distance, according to the National Biogas Programme of Ethiopia at most $30 \mathrm{~min}$ away from the residence. The key informants validated the results of the household survey by disclosing that the suitability of a site and the availability of space limit the uptake of biogas technology by households. In some locations, because of the rocky nature of the surface, it is difficult or more labor-demanding and expensive to dig a pit for the digester; consequently households are reluctant to adopt the technology. The participants of focus group discussion also underlined that the spillover effect of failed digesters, inadequate training and poor follow up of technicians and inadequate maintenance services have prevented widespread dissemination of the technology. Similar results have been reported regarding barriers to the large-scale adoption of digesters in different sub-Saharan African countries. For instance, in Tanzania, inadequate water availability, poor performance of digesters and poor follow up were reported to be major challenges for the widespread use of biogas technology [24, 26]. Similar challenges on a smaller scale are also reported from other sub-Saharan African and Asian countries [41-46].

Looking at the future prospects of biogas technology, the surveyed households stated that the presence of scarcity of solid fuels (44.5\%), the multiple use of biogas (40\%), and the availability of cheap feedstocks (39\%) are the favorable conditions and pressing factors for the future promotion of the sector (Table 4). Equally important, the existence of government subsidy for the technology and the ever rising price of both solid biomass and modern energy sources were also considered by the respondents as an opportunity for the future promotion of the technology. For too many people, the scarcity of solid fuels, dependence on too few forested areas, along with the large number of households with indoor and outdoor fed cattle would help to make biogas a suitable and accessible technology for smallholder farm households. The result of the descriptive statistics also shows that households that adopted biogas technology are spatially located far away from the nearest firewood collection site as compared to the non-adopters. Biogas users have to spend on average $5 \mathrm{~h}$ (round trip) from their house to the fuel wood collection site and the non-adopters $4 \mathrm{~h}$. This signals that the unavailability of fuel woods (forests and woodlots) in a nearby area compels farmers to look into other alternative energy sources such as biogas energy instead of fully relying on scarce solid biomass energy sources. 
As shown in Table 4, the availability of cheap feedstock was mentioned as one of the favorable conditions for the further promotion of biogas technology by $39 \%$ of the surveyed households. This could probably be due to the fact that the average cattle holding of the surveyed households is found to be five heads for both biogas adopters and non-adopters which is slightly higher than the minimum head of cattle required to operate a $6 \mathrm{~m}^{3}$ biogas digester, four heads of cattle according to national biogas program of Ethiopia. Hence, the presence of cheap and locally available feedstock (cattle manure) which is associated with relatively larger cattle holding would make the promotion and diffusion of biogas technology more promising. A report by the CSA [47] in this regard also shows that the total estimated cattle in the Tigrai region is nearly 4.6 million, and out of this about 3.8 million are aged 2 years and older. The region has, therefore, an untapped potential for biogas technology since cattle dung has been used as the major source of feedstock for anaerobic digestion. The biogas digesters in the study areas are mainly loaded with cattle manure, human excreta, and water. Besides, strict tree cutting monitoring and zero grazing policies in the country could indirectly assist biogas promotion. Parallel to the findings of the current study, Kamp and Forn [20] assert that a scarcity of firewood, deforestation, depletion of soil nutrients, and erosion are the drivers for more biogas technology in the future. Moreover, suitable agro-ecology and widespread rearing of livestock are reported to be among the favorable conditions for biogas technology dissemination in eastern Africa [27, 45]. The pressing factors, such as the increase in the prices of fossil fuels, wood fuels, and fertilizers in sub-Saharan Africa would also make for a brighter future for biogas technology promotion in the region [27, 48], which is in agreement with the findings of the current study.

\section{Economic benefits of the domestic biogas technology}

Tables 6 and 7 present a summary of the outcomes of the propensity score matching using the four matching algorithms. It includes the nearest neighbor, radius, kernel, and stratification. This paper adopts the four matching methods for the reason that any comparison study is free to use any of the matching algorithms, and none of them is superior to the others, but their joint consideration provides a way to assess the robustness of the estimates of the outcome variables [39].

Table 5 shows the estimated coefficients of the propensity score, which are used as a pre-requisite for the estimation of the outcome variables. The diagnostic test confirms the overall fitness of the model as Prob $>$ chi $2=0.000$. The age of the household head, the sex of the household head, the education level of the household head, the income, the household size, the availability of solid fuels, and electricity are found to be the key factors affecting the probability of adopting biogas technology (Table 5). Household heads that are older and with relatively higher income were found to be more interested in installing the biogas technology. This is probably due to the possibility of a better wealth accumulation as people get older, and thereby can afford to install a biogas digester. Females were more likely to adopt biogas compared to their male counterparts. The reason why women are more interested in the adoption of biogas technology could be due to the fact that women are more responsible for collecting firewood and are also the prime victims of indoor air pollution in the kitchen. Households who do not have solid fuel sources in nearby areas were found to be more motivated to adopt a biogas digester. Besides, households who use electricity were also found to be more interested in adopting biogas technology compared to those who do not. The reason for the complementarity between electricity and biogas energy may arise due to a low disposable income of rural households in general. As a result, they may choose to use electricity for only lighting purposes and the relatively cheaper biogas energy for cooking and boiling.

Table 6 presents the effect of biogas energy utilization on energy expenditure using four matching methods. The results vary as the matching algorithm changes, although all methods reached the same conclusion regarding the impact of biogas energy technology on reducing energy expenditure of rural households. This is because different matching methods employ different principles and ways of computing the average treatment effects. For instance, using the nearest neighbor method, 200 treated observations were matched to 93 comparison observations. Whereas, in both radius and kernel methods, 200 comparison observations were matched to 200 treated observations which is one to one. Similarly, 199 control observations were matched to 200 treated observations using a stratification matching method (Table 6). Despite the variation in numerical values, all matching methods confirm that the biogas technology has significantly influenced the energy expenditure of smallholder farmers. As shown in Table 6, the average monthly energy expenditure of biogas adopters was less by $\mathrm{ETB}^{3} 108.36,59,98$, and 82.4 than that of non-adopters $(P<0.01)$ using the nearest neighbor, radius, kernel, and stratification methods respectively. The average reduction in energy expenditure ranges from 20 to $36 \%$.

The paper also attempts to compare the share of annual energy expenditure from the total annual income between biogas adopter and non-adopter households. The share of annual energy expenditure of biogas users was found to be on average $1.8 \%$ of their total annual income while it was $3.1 \%$ for the non-biogas user 
Table 5 Coefficients of propensity score (standard errors in parentheses)

\begin{tabular}{|c|c|c|}
\hline \multirow[t]{2}{*}{ Explanatory variables } & \multicolumn{2}{|l|}{ Biogas adoption } \\
\hline & Coefficient & $P$ value \\
\hline Age & $0.12(0.07)$ & 0.07 \\
\hline Dummy male & $-0.357(0.212)$ & 0.09 \\
\hline Family size & $0.065(0.043)$ & 0.12 \\
\hline Education & $0.046(0.029)$ & 0.1 \\
\hline Cattle holding & $-0.02(0.026)$ & 0.39 \\
\hline Annual income & $0.000026(7.9 \mathrm{e}-06)$ & 0.001 \\
\hline Distance between home and firewood collection site & $0.00074(0.00047)$ & 0.1 \\
\hline Distance between home and watering point & $-0.0017(0.0014)$ & 0.2 \\
\hline Distance between home and nearest market & $-0.008(0.006)$ & 0.22 \\
\hline Availability of electricity & $0.71(0.199)$ & 0.000 \\
\hline Farm size & $-0.08(0.12)$ & 0.5 \\
\hline Medium fertility of soil & $0.07(0.16)$ & 0.6 \\
\hline Poor fertility of soil & $-0.378(0.168)$ & 0.02 \\
\hline Farm location & $2.27(0.57)$ & 0.000 \\
\hline Zero grazing & $1.09(0.46)$ & 0.01 \\
\hline Extension service & $0.006(0.008)$ & 0.44 \\
\hline Constant & $-7.78(1.68)$ & 0.000 \\
\hline Obs. $=400$ & LR chi2 $(12)=71.36$ & $\begin{array}{l}\text { Prob }>\text { chi } 2=0.000 \\
\text { likelihood }=-241.58\end{array}$ \\
\hline
\end{tabular}

households. The energy costs of biogas users is thus much lower than that of non-adopters since the feedstocks for biogas digestion particularly cattle manure and human excreta are mostly supplied from own sources, if not obtained at low cost. On the contrary, the non-biogas users are forced to allocate a significant proportion of their income to acquire traditional energy sources such as firewood, charcoal, animal dung, and other biomasses. It can, therefore, be inferred that the primary impact of biogas plants is a significant reduction in fuel expenditure of rural households particularly for cooking and lighting purposes. Moreover, the logit regression result presented in Table 5 gives an important insight to the energy transition model. The current study finds that households which use electricity are also found to be more likely to adopt biogas energy. This finding degrades the theory of the energy ladder, which states households tend to completely switch to modern energy (electricity) from traditional and transitional energy sources. Rural households with access to electricity usually use electric power for lighting but rarely for cooking and baking purposes. The fact that rural households have less interest in using electricity for cooking and baking purposes, other than for lighting, is because the price of electricity service is much more expensive and rural households cannot afford to pay for such type of services as they have less disposable income. Instead, biogas can be used for both home lighting and for other domestic energy needs such as cooking food and boiling water. Therefore, an energy mix, especially supplementing electricity service with other renewable energy sources such as biogas, seems to be a viable strategy for rural households to gratify their energy demands. The findings of the current study confirm that households tend to use a mix of energy sources instead of relying on a single fuel. This supports the theory of energy stacking.

Similar results have been reported from various developing countries. In Rwanda, for instance, energy expenditure is reduced on average by $31-32 \%$ as a result of using biogas

Table 6 Effect of biogas energy utilization on energy expenditure of households

\begin{tabular}{lllll}
\hline Matching method & Treated observation & Control observation & Energy expenditure (ATT) & $t$ value \\
\hline Nearest neighbor & 200 & 93 & $-108.35^{* * *}$ & $-59^{* * *}$ \\
Radius & 200 & 200 & $-98.2^{* * *}$ & 3.42 \\
Kernel & 200 & 200 & $-82.4^{* * *}$ & 4.17 \\
Stratification & 200 & 199 & 3.6 \\
\hline
\end{tabular}

*****, and * denote value significant at $1 \%, 5 \%$, and $10 \%$ respectively 
energy [49], which is roughly similar to the findings of the current study. Likewise, the domestic biogas program has resulted in a reduction of households' energy expenditure on average by $45 \%$ in Indonesia [50] which is slightly higher than the finding of the current study.

Apart from analyzing the impact of the biogas initiative on energy-related expenditures, the study focuses on the synergy between biogas technology and agriculture. As the potential of the target households for future biogas promotion is in rural areas in which agricultural sectors remains the sole source of livelihood, this study took a closer look at the possible linkages between agriculture and biogas digesters by computing the effects of bio-slurry utilization on crop yield and demand for chemical fertilizer. The dominant crops grown in the study sites are cereals; mainly wheat, barely, teff, and maize. The types of chemical fertilizers that have been utilized by the farmers are DAP and UREA.

Using the four matching methods stated above, the annual crop yield of biogas user households was found to be on average higher by 1.7, 1.4, 1.5, and 1 quintals/year/ household as compared to non-users, respectively, due to the application of a bio-slurry treatment on crop fields. It is important to note that field trials are reported to be an appropriate methodology to compare the yield differences of crops as a result of a bio-slurry application instead of applying such an observational study. However, field trials could not show the overall impact of a bio-slurry application on the crop yield of participants of the initiative (on a community and even a household level). In such cases, an impact assessment methodology is more important than field trials, i.e., this analysis method is, therefore, the appropriate method for the current study. Nevertheless, the paper may suffer from some level of bias since all factors that affect crop production could not be fully controlled in such an observational study and may therefore influence the accuracy of the above stated findings. On the other hand, the annual uptake of chemical fertilizers of biogas users was found to be on average less by $0.34,0.22,0.28$, and 0.25 quintal/ household compared to non-user households using the above stated matching methods in that order.

Unlike energy expenditure, the effects of a bio-slurry fertilizer application on the crop yield and substitution of chemical fertilizer are not fully materialized. The productivity effect of the bio-slurry fertilizer was found to be significant $(P=0.1)$ using the radius and kernel matching methods, whereas the results of nearest neighbor and stratification show no significant difference. Besides, there was no significant difference to the chemical fertilizer uptake of bio-slurry user and non-user households using all matching methods, which signals no significant substitution effect as shown in Table 7. A considerable number of households were observed to have a low level of understanding of the importance and utilization of bio-slurry as a fertilizer. Only $20 \%$ of the biogas adopters were found to be users of bio-slurry on their plots. Lack of adequate knowledge and social taboo were among the frequently stated reasons for not yet using a bio-slurry by the remaining $80 \%$ of biogas adopters. It was observed during the survey that farmers usually dispose the bio-slurry into an open pit without adequate care to protect nutrient evaporation. The key informants also revealed that the application of a bio-slurry is often done inaccurately and at the wrong time. Furthermore, the masons and the biogas energy promotion experts usually train the biogas users on bio-slurry utilization although the focus and expertise of these personnel is not related to agriculture. This gives the insight that bio-slurry utilization is poorly taught to biogas users by masons, energy promoters and technicians which are in fact outsiders in terms of the field of agriculture.

The key informants further stressed that poor technical knowledge, low awareness, and acceptance of this type of fertilizer and poor extension support coupled with some traditional taboos are to be claimed for the insignificant contribution of bio-slurry to crop productivity and substitution of chemical fertilizer. Besides, the focus group discussants underlined that the negative connotation attached to the bio-slurry, as it is produced from cattle dung and faecal sludge, hinders its rate of application. These may contribute to not fully materialized benefits. Furthermore, the fact that the Bureau of Agriculture and Rural Development of the region did not play an active role in the implementation of the domestic biogas program of the country might have also contributed to the technical faults on the bio-slurry application and the knowledge gaps. This may have also led to the insignificant contribution of the bio-slurry to the existing cropping system.

Previous studies reported parallel findings in this regard. In line with the current finding, in Rwanda, for instance, the benefits of the national domestic biogas program include meeting all the energy needs for cooking and reducing the energy expenditure of households $[49,51]$. In addition to this, Mwakaje [24] reveals that the adoption of biogas energy in Tanzania and Rwanda has helped in empowering the socio-economic status particularly by enhancing the income of households and creating job opportunities. Another study by Warnars and Oppenoorth [52] indicated that using bio-slurry leads to a higher crop yield increment despite its productivity effect varying from crop to crop.

It is, however, important to note that the results of the current study should be calibrated using experimental studies, such as field trials, as the estimates from such observational studies may not be able to control all unobserved biases which could affect the robustness of the estimated results. 
Table 7 Effect of bio-slurry application on crop yield and uptake of chemical fertilizer (t-value in parentheses)

\begin{tabular}{lllll}
\hline Matching method & Treated observation & Control observation & Crop yield (ATT) & Chemical fertilizer uptake (ATT) \\
\hline Nearest neighbor & 50 & 25 & $1.7(1.5)$ & $-0.34(0.6)$ \\
Radius & 47 & 71 & $1.46(1.87)^{*}$ & $-0.22(1.256)$ \\
Kernel & 50 & 71 & $1.56(1.9)^{*}$ & $-0.28(1.6)$ \\
Stratification & 50 & 71 & $1.06(1.24)$ & $-0.255(1.96)$ \\
\hline
\end{tabular}

*Denotes values significant at $10 \%$

\section{Conclusions}

The comparison of energy expenditure between biogas user and non-user households shows a substantial difference. The average monthly energy expenditure of biogas user households has been reduced by $20-36 \%$ as a result of partially switching to biogas energy particularly for lighting and cooking purposes. Furthermore, the study finds the existence of a positive crop yield premium of roughly about 1.5 quintal/year/household as a result of using bio-slurry as a fertilizer Such a reduction in energy expenditure and an increment in crop yield have a positive contribution to enhance the real income of households. These findings have important implications on the further promotion of family-sized biogas digesters. This means that biogas technology should not only be promoted for the purpose of supplying clean energy but also for fostering the income of rural households by reducing the energy expenditure and enhancing crop productivity. Despite this, the overall effect of a bio-slurry application on crop productivity and substitution of chemical fertilizer was not as much as expected due to the poor management and knowledge in bio-slurry utilization. The installed biogas units are confronted by an inadequate energy production, frequent damage, and an inadequate institutional support for maintenance and repair that hinders the transition from solid wood fuels to better energy facilities such as biogas. The key factors that limit the extension of the biogas technology to potential biogas adopters are the presence of failed and damaged digesters, an inadequate plot of land for digester construction and the water availability problem. In the face of such barriers, there are still enabling environments for the widespread use of the technology such as a scarcity of solid fuels, a rise in price of modern energy sources, the availability of a cheap input for biogas production, and multi-faceted use of the technology.

The leading agency, National Biogas Programme of Ethiopia, which is in charge of biogas promotion, should ensure the active engagement of relevant agencies such as environmental protection, natural resources management, agriculture, and health care at a district and community levels in order to overcome the challenges facing the technology and to realize its multifaceted benefits. The actors involved in this biogas program are also advised to quickly focus on addressing the technical and attitudinal barriers hampering biogas energy and bio-slurry utilizations. Further plot level and crop-specific research work is recommended to explore the contribution of domestic biogas to crop productivity and climate smart agriculture.

\section{Endnotes}

${ }^{1} \mathrm{~A}$ "tabia" in this paper refers to the smallest administration unit in Tigrai next to a district

${ }^{2}$ Tsimad is a local unstandardized measurement of size of farm plots (one tsimad is roughly equivalent to $0.25 \mathrm{ha}$ )

${ }^{3}$ Ethiopian Birr (ETB), currency of Ethiopia (US\$1 = 27.2 ETB as of December, 2017 exchange rate)

\section{Additional file}

Additional file 1: Raw data collected from surveyed household heads. (XLSX $91 \mathrm{~kb})$

\section{Abbreviations}

Eq.: Equation; ETB: Ethiopian birr; hh: Household; UNDP: United Nations Development Programme; WHO: Word Health Organization

\section{Acknowledgements}

The author is very grateful to the Mekelle University and Pan African University for funding part of the data collection costs. The author extends his gratitude to the enumerators and households who participated in this study. The author is thankful to the anonymous reviewers and editor of the journal for their helpful and critical recommendations to the earlier version of this paper. The author also extends appreciation to Mr. Haftu Kahsay for his invaluable contribution to correct grammatical errors.

\section{Funding}

The fund for data collection was obtained from Mekelle University and Pan African University.

\section{Availability of data and materials}

The raw data has been submitted online as Additional file 1.

\section{Authors' contributions}

HE developed the concept, designed the data collection instruments, and supervised data collection. In addition, data analysis and the interpretation of the results and writing this manuscript were carried out by the same author. The author also read and approved the final manuscript.

\section{Competing interests}

The author declares that he has no competing interests.

\section{Publisher's Note}

Springer Nature remains neutral with regard to jurisdictional claims in published maps and institutional affiliations. 


\section{Received: 8 February 2018 Accepted: 12 September 2018} Published online: 01 October 2018

\section{References}

1. WHO \& UNDP (2009) The energy access situation in developing countries." World Health Organization and the United Nations Development Programme, New York. Accessed 15 December 2017

2. Arnold MJE, Köhlin G, Persson R (2006) Woodfuels, livelihoods, and policy interventions: changing perspectives. World Dev 34:596-611

3. Fritsche UR, Sims REH, Monti A (2010) Direct and indirect land use competition issues for energy crops and their sustainable production-an overview. Biofuels Bioprod Biorefin 4:692-704

4. liyama M (2013) Charcoal: a driver of dryland forest degradation in Africa. World Agroforestry Centre, ICRAF Fact Sheet Nairobi, Kenya

5. FAO (2010) Global forest resources assessment: country report Ethiopia. Rome, Italy. Available at www.fao.org/docrep/013/i1757e/i1757e.pdf Accessed 10 June 2017

6. International Energy Agency (2014) Africa Energy Outlook: special report focus on energy prospects in sub-Saharan Africa. Paris, France. Available at https://www.iea.org/publications/freepublications/publication/WEO2014_ AfricaEnergyOutlook.pdf. Accessed 18 Sept 2017

7. Legros Gl, Havet N, Bruce S, Bonjour K, Rijal M, Takada DC (2009) The energy access situation in developing countries, New York, United Nations Development Programme

8. Parawira W (2009) Biogas technology in sub-Saharan Africa: status, prospects and constraints. Rev Environ Sci Biotechnol 8:187-200

9. Mohammed YS, Mustafa MW, Bashir N (2013) Status of renewable energy consumption and developmental challenges in sub-Sahara Africa. Renew Sust Energ Rev 27:453-463

10. Ethiopian Rural Energy Development and Promotion Centre (EREDPC) (2008) A working document on National Biogas Programme Ethiopia Programme implementation. Addis Ababa, Ethiopia. Available at http://www.bibalex.org/ Search4Dev/files/284294/116537.pdf. Accessed 10 June 2017

11. Africa Biogas Partnership Programme. Available at http://www.snv.org/ project/africa-biogas-partnership-programme-African Biogas Partnership Programme. Accessed 28 Sept 2017

12. International Energy Agency (2011)World energy outlook :energy for all, financing access to the poor. Paris: Available at https://www.International Energy Organization.org/publications/freepublications/publication/ WEO2011_WEB.pdf. Accessed 18 Sept 2017

13. International Energy Agency (2010) World energy outlooks: a working document on energy for cooking in developing countries. Available at www.worldenergyoutlook.org/media/weo2010.pdf. Accessed 18 Sept 2017

14. Mengistu MG, Simane B, Eshete $G$, Workneh TS (2016) A review on biogas technology and its contributions to sustainable rural livelihood in Ethiopia. Renew Sust Energ Rev 48:306-316

15. Luostarinen S, Normak A, Edström M (2011) Overview of biogas technology. Overview of Biogas Technology Baltic manure WP6 Energy potentials: 47

16. Christiaensen L, Heltberg R (2014) Greening China's rural energy: new insights on the potential of smallholder biogas. Environ Dev Econ 19:8-29

17. Cuéllar AD, Webber ME (2008) Cow power: the energy and emissions benefits of converting manure to biogas. Environ Res Lett 3:034002

18. Axaopoulos P, Panagakis P (2003) Energy and economic analysis of biogas heated livestock buildings. Biomass Bioenergy 24:239-248

19. Köhlin, Gunnar, Sills EO, Pattanayak SK, Wilfong C (2011) "Energy, gender and development: what are the linkages? Where is the Evidence? Available at https://openknowledge.worldbank.org/handle/ 10986/3564. Accessed 15 Dec 2017

20. Kamp LM, Forn EB (2016) Ethiopia's emerging domestic biogas sector: current status, bottlenecks and drivers. Renew Sust Energ Rev 60:475-488

21. Eshete G, Sonder K, ter Heegde F (2006) Report on the feasibility study of a national programme for domestic biogas in Ethiopia. SNV Netherlands Development Organization, Addis Ababa. Available at http://www.bibalex.org/ Search4Dev/files/338849/172350.pdf. Accessed 10 June 2017

22. Kelebe HE, Ayimut KM, Berhe GH, Hintsa K (2017) Determinants for adoption decision of small scale biogas technology by rural households in Tigrai, Ethiopia. Energy Econ 66:272-278

23. Mengistu MG, Simane B, Eshete G, Workneh TS (2016) Institutional factors influencing the dissemination of biogas technology in Ethiopia. J Hum Ecol 55:117-134
24. Mwakaje AG (2008) Dairy farming and biogas use in Rungwe district, Southwest Tanzania: a study of opportunities and constraints. Renew Sust Energ Rev 12:2240-2252

25. Murphy JT (2001) Making the energy transition in rural East Africa: is leapfrogging an alternative? Technol Forecast Soc Chang 68:173-193

26. Mwirigi J, Balana BB, Mugisha J, Walekhwa P, Melamu R, Nakami S, Makenzi P (2014) Socio-economic hurdles to widespread adoption of small-scale biogas digesters in Sub-Saharan Africa. Biomass and Bioenergy 70:17-25

27. Walekhwa PN, Mugisha J, Drake L (2009) Biogas energy from family-sized digesters in Uganda: critical factors and policy implications. Energy Policy 37:2754-2762

28. Kabir H, Yegbemey RN, Bauer S (2013) Factors determinant of biogas adoption in Bangladesh. Renew Sust Energ Rev 28:881-889

29. Amigun B, Parawira W, Musango JK, Aboyade AO, Badmos AS (2012) Anaerobic biogas generation for rural area energy provision in Africa. In Biogas. InTech

30. Ouedraogo B (2006) Household energy preferences for cooking in urban Ouagadougou, Burkina Faso. Energy Policy 34(18):3787-3795

31. Heltberg R (2005) Factors determining household fuel choice in Guatemala. Environ Dev Econ 10:337-361

32. Odihi J (2003) Deforestation in afforestation priority zone in SudanoSahelian Nigeria. Appl Geogr 23:227-259

33. Horst GH, Hovorka AJ (2008) Reassessing the "energy ladder": household energy use in Maun, Botswana. Energy Policy 36:3333-3344

34. Mekonnen A, Zenebe G, Minale K, Kolin G (2009) Income alone does not determine adoption and choice of fuel types. Policy brief: Environment for Development (EfD). Available at www.efdinitiative.org/sites/default/files/ urban20feul20choice20brief.pdf. Accessed 12 May 2018

35. Ogwumike FO, Uzughalu UM, Abiona GA (2014) International Journal of Economics and Policy 4

36. Masera OR, Saatkamp BD, Kammen DM (2000) From linear fuel switching to multiple cooking strategies: a critique and alternative to the energy ladder model. World Dev 28:2083-2103

37. Berhe M, Dana H, Tesfay G, Catherine K (2017) Factors influencing the adoption of biogas digesters in rural Ethiopia. Energy Sustain Soc 7:10 https://doi.org/10.1186/s13705-017-0112-5

38. Watson, J. (2001). How to determine a sample size: Tipsheet \#60, University Park, PA: Penn State cooperative extension. Available at: http://www. extension.psu.edu/evaluation/pdf/TS60.pdf. Accessed 10 June 2017

39. Becher SO, Ichino A (2002) Estimation of average treatment effects based on propensity scores. Stata J 2(4):358-377

40. National Biogas Programme of Ethiopia (2016) Unpublished report on performance of domestic biogas diffusion

41. Chen L, Zhao L, Ren C, Wang F (2012) The progress and prospects of rural biogas production in China. Energy Policy 51:58-63

42. Bhat PR, Chanakya HN, Ravindranath NH (2001) Biogas plant dissemination: success story of Sirsi, India. Energy Sustain Dev 5:39-46

43. Raha D, Mahanta P, Michèle LC (2014) The implementation of decentralised biogas plants in Assam, NE India: the impact and effectiveness of the National Biogas and manure management Programme. Energy Policy 68:80-91

44. Kranert M, Kusch S, Huang J, Fischer K (2012) Anaerobic digestion of waste. In: Waste to Energy. Springer, London, pp 107-135

45. Njoroge (2002) Kuria D (2002) evolution of biogas technology in South Sudan; current and future challenges. In: Proceedings of the biodigester workshop march

46. Huba EM, Fall PA, Sanogo O, Kabore G, Bracken P (2007) Feasibility study for a national domestic biogas programme in Burkina Faso. Deutsche Gesellschaft fur Technische Zusammenarbeit. Available at https:/energypedia.info/images/ 3/3e/Domestic Biogas_Program in_Burkina_Faso.pdf. Accessed 28 Apr 2018

47. CSA (Central Statistical Agency of Ethiopia) (2016) Report on agricultural sample survey of Ethiopia, Addis Ababa. Available at www.csa.gov.et/ehioinfointernal?download=816:livestock-report-2009-ec-2016. Accessed 17 Sept 2017

48. Avery L, Joanne S, Tumwesige V (2011) Small-scale biogas digester for sustainable Energy production in Sub-Saharan Africa. In The 1st World Sustainability Forum. Basel, Multidisciplinary Digital Publishing Institute

49. Bedi AS, Pellegrini L, Luca Tasciotti $L$ (2015) The effects of Rwanda's biogas program on energy expenditure and fuel use. World Dev 67:461-474

50. Bedi AS, Sparrow R, Tasciotti $L$ (2017) The impact of a household biogas programme on energy use and expenditure in East Java. Energy Econ 68:66-76 
51. Munyehirwe, Anicet, and P. Kabanda. (2008). Performance assessment of institutional biogas systems in Rwanda. Inclusive Business and Consultance Ltd. GIZ, Rwanda. Available at https://cpia.afdb.org/?page=results\&subpage= profile\&indicator...2008. Accessed 10 June 2017

52. Warnars and Oppenoorth (2014) a working paper on bio-slurry as a supreme fertilizer. Available at https://www.hivos.org/sites/default/files/ publications/bioslurry_a_supreme_fertiliser_a_study_on_bioslurry_results_ and_uses.pdf. Accessed on 18 Sept 2017

- fast, convenient online submission

- thorough peer review by experienced researchers in your field

- rapid publication on acceptance

- support for research data, including large and complex data types

- gold Open Access which fosters wider collaboration and increased citations

- maximum visibility for your research: over $100 \mathrm{M}$ website views per year

At $\mathrm{BMC}$, research is always in progress.

Learn more biomedcentral.com/submissions 